\title{
Amorfrutin-type phytocannabinoids from Helichrysum umbraculigerum
}

Federica Pollastro, ${ }^{1}$ Luciano De Petrocellis, ${ }^{2}$ Aniello Schiano-Moriello, ${ }^{2}$ Giuseppina Chianese, ${ }^{3}$ Heino Heyman, ${ }^{4,}$ Giovanni Appendino, ${ }^{1 *}$ and Orazio Taglialatela-Scafati ${ }^{3 *}$

${ }^{1}$ Dipartimento di Scienze del Farmaco, Università del Piemonte Orientale, Via Bovio 6, 28100 Novara, Italy

${ }^{2}$ Endocannabinoid Research Group, Institute of Biomolecular Chemistry, Consiglio Nazionale delle Ricerche, Via Campi Flegrei 34, 80078 Pozzuoli (NA), Italy

${ }^{3}$ Dipartimento di Farmacia, Università di Napoli Federico II, Via Montesano 49, 80131 Napoli, Italy

${ }^{4}$ Department of Plant Science, University of Pretoria, Pretoria 0002, South Africa

*Corresponding Authors : Tel: +39081678509 (OTS) and +390321 375744(GA); fax: +39081678552 (OTS) and +390321 375621(GA).E-mail address: giovanni.appendino@uniupo.it; scatagli@unina.it (OTS);

\section{Graphycal Abstract}

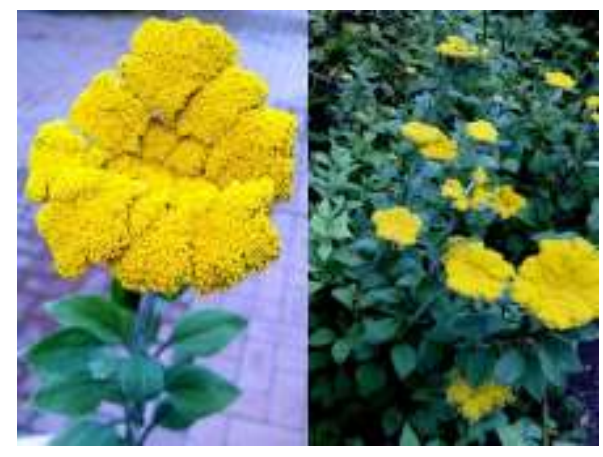<smiles>CCC(C)C(=O)Oc1cc(CCc2ccccc2)cc(O)c1CC=C(C)C</smiles><smiles>CC1(C)CCc2c(O)cc(CCc3ccccc3)cc2O1</smiles><smiles>CCCC(=O)c1c(O)cc(O)c(C/C=C(\C)CCC=C(C)C)c1O</smiles> 


\begin{abstract}
:
Helichrysum umbraculigerum Less. has been reported to be a prolific producer of phytocannabinoids from the alkyl-, aralkyl-, normal-, and abnormal types. Investigation of an acetone extract from the aerial parts of the plant afforded two novel amorfrutin-type phytocannabinoids $(\mathbf{3 b}, \mathbf{4})$ and the new geranylated phloroglucinol 5a. The presence of cannabigerol (CBG, 1a) and its acidic precursor (pre-CBG, CBGA, 1b), previously reported from this plant, could not be confirmed, but the phenethyl analogue of CBG (Heli-CBG, 2a) and the methyl ester of its carboxylated version (2b) were isolated. Heli-CBG (2a) was assayed against a series of metabotropic $\left(\mathrm{CB}_{1}\right.$ and $\left.\mathrm{CB}_{2}\right)$ - and ionotropic (thermo-TRPs) targets of phytocannabinoids, comparing its profile with the one of cannabigerol (CBG). A decreased affinity for cannabinoid receptor was observed, along with substantial retention of the thermo-TRP profile. The biogenetic relationships between the isoprenylated phenolics from $H$. umbraculigerum are discussed, highlighting the relevance of this species for biogenetic investigations on phytocannabinoids.
\end{abstract}

Keyword: Helichrysum umbraculigerum; aralkyl phytocannabinoids; amorfrutins, cannabigerol, cannabinoid receptors, thermo-TRPs

\title{
1. Introduction
}

As the result of the convergence of two modular pathways (polyketides and isoprenoids), phytocannabinoids occur in a variety of chemotypes, distinct on the basis of their derivation from an aliphatic or an aromatic ketide starter (alkyl- and aralkyl phytocannabinoids, respectively) and of the degree of oligomerization of the isoprenyl residue. ${ }^{1}$ Although traditionally associated to cannabis (Cannabis sativa L.), phytocannabinoids have actually a broader, although point-like, 
distribution in Nature, encompassing not only higher plants, but also liverworts and fungi. ${ }^{1}$ For this reason, and to avoid confusion with the pharmacological meaning of the name "cannabinoid" (modulator of the cannabinoid receptors $\mathrm{CB} 1$ and $\mathrm{CB} 2$ ), the name phytocannabinoids has been proposed in alternative to simply "cannabinoids", that overemphasizes the relationship with $C$. sativa. ${ }^{1}$ At least in plants, a single species typically accumulates only a limited range of chemotypes. Thus, C. sativa and rhododendrons produce exclusively alkyl phytocannabinoids, ${ }^{1}$ while aralkyl phytocannabinoids are typical of some leguminous plants from the genera Amorpha, Glycyrrhiza and Macherium. ${ }^{1}$ Phytocannabinoids have a pleiotropic bioactivity profile, as exemplified by the metabotropic cannabinoid receptors $\mathrm{CB}_{1}$ and $\mathrm{CB}_{2}$, the ionotropic thermo-TRP ion channels, and the transcription factors from the PPAR family. ${ }^{2}$ Modulation of CBs is typical of the alkyl phytocannabinoid $\Delta^{9}$-THC, while the one of PPARs is the hallmark of amorfrutins, a class of bibenzyls belonging to the aralkyl phytocannabinoid chemotype. ${ }^{3}$ Surprisingly, phytocannabinoids from both the alkyl- and the aralkyl series have been reported from the SouthAfrican plant Helichrysum umbraculigerum Less. ${ }^{4}$ Although only non-narcotic compounds were isolated, some African Helichrysum species are used for ritual inebriating fumigations, a use strongly reminiscent of the ones described by the ancient authors for cannabis, ${ }^{5}$ and this folk use presumably underlies the trade of some South-African Helichrysum species for recreational narcotic purposes. ${ }^{6}$ As part of our investigation on phytocannabinoids, we have phytochemically profiled an acetone extract from H. umbraculigerum, a plant reported to be the most abundant natural source of cannabigerol (1a), ${ }^{4}$ the precursor of all members of the alkylcannabinoid family.

\section{Results and Discussion}

An acetone extract from the aerial parts (leaves and flowers) of $H$. umbraculigerum was decarboxylated under the classic conditions used for phytocannabinoids (heating at $120^{\circ} \mathrm{C}$ for two hours $)^{7}$. Fractionation by a combination of gravity column chromatography (GCC), semi- 
preparative and analytical HPLC afforded, overall, thirteen phenolics, sorted out into resorcinoids (2a-2b, 3a-3d, 4) and phloroglucinoids $(\mathbf{5 a - 5 b}, \mathbf{6}, \mathbf{7 a - 7 b}, \mathbf{8})$. Interestingly, all resorcinoids are derived from an aromatic ketidic starter, and belong to the bibenzyl type of aralkyl phytocannabinoids. Conversely, with the exception of the flavanone glabranin $(\mathbf{8})$, all phloroglucinoids derive from an aliphatic ketide starter. Thus, within $H$. umbraculigerum there seems to exist a clear distinction between the Claisen-type and the aldol-type aromatization mode of polyketides, with, respectively, formation of resorcinoids or phloroglucinoids depending on the aliphatic or aromatic nature of the starter, as highlighted by comparison of $\mathbf{2 a}$ and $\mathbf{5 a}$.<smiles>[R]c1c(CCCCC)cc(O)c(C/C=C(/C)CCC=C(C)C)c1O</smiles>

$\mathrm{R}$

1a $\mathrm{H}$

1b $\mathrm{COOH}$<smiles></smiles>

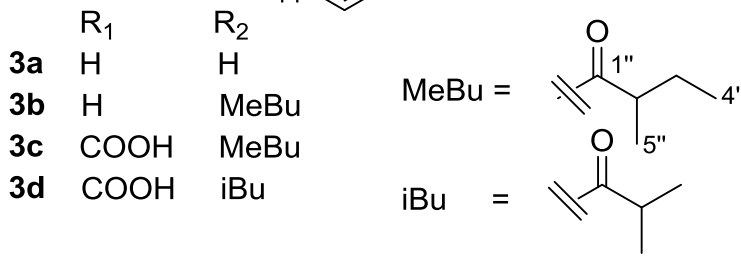<smiles>[R]c1cc(CCc2ccccc2)c(O)c(O)c1CC=C(C)CCC=C(C)C</smiles>

2a $\mathrm{H}$

2b COOMe<smiles>CC1(C)CCc2c(O)cc(CCc3ccccc3)cc2O1</smiles> 


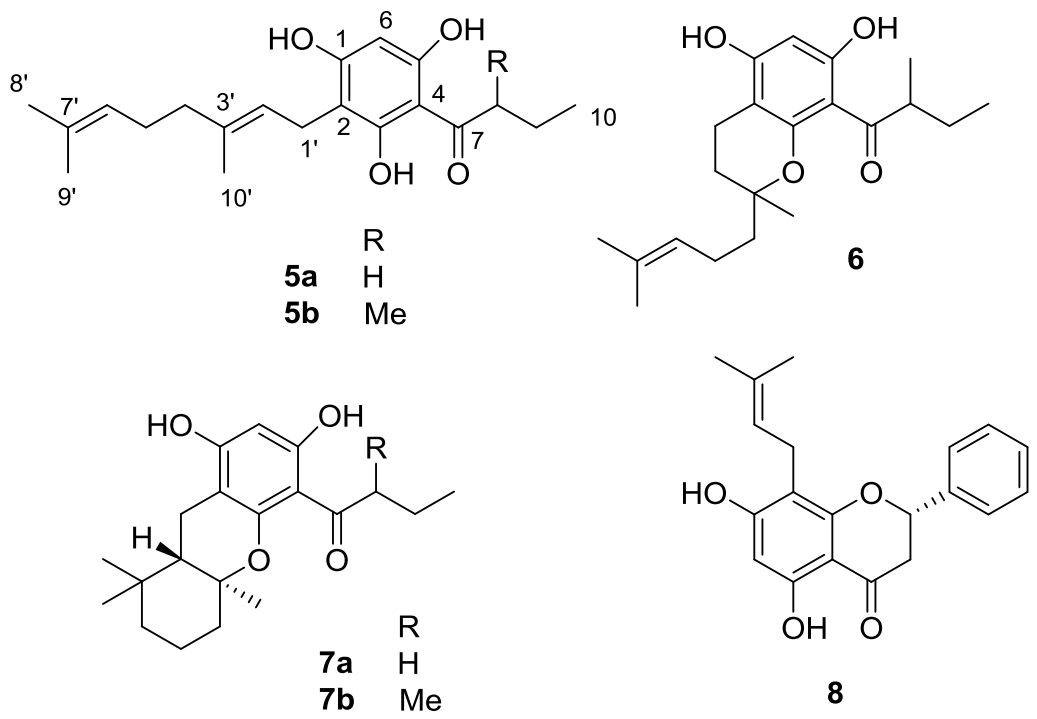

The bibenzyls 2a,b, and 3a,c,d are known and had been previous isolated from $H$. umbraculigerum $^{4}$ and/or related species, ${ }^{8}$ while $\mathbf{3 b}$ and $\mathbf{4}$ are new, as is the phloroglucinoid $\mathbf{5 a}$.

Compound $\mathbf{3 b}$ was isolated as a colorless amorphous solid with molecular formula $\mathrm{C}_{24} \mathrm{H}_{30} \mathrm{O}_{3}$ (positive ions HR-ESIMS). ${ }^{1} \mathrm{H}$ NMR spectrum of $\mathbf{3 b}$ strongly suggested its bibenzyl resorcinoid nature, hallmarked by the five proton cluster at $\delta_{\mathrm{H}} 7.35-7.15$, assigned to a monosubstituted phenyl group, by the two methine resorcinyl resonances $\left(\delta_{\mathrm{H}} 6.56\right.$ and 6.44 , both bs) and by two overlapped methylene signals resonating at $\delta_{\mathrm{H}} 2.83-2.85$. The ${ }^{1} \mathrm{H}$ NMR spectrum of $\mathbf{3 b}$ was completed by the typical resonances of a prenyl unit and of a 2-methylbutanoyl group. Once the last two spin systems were secured by means of the 2D COSY spectrum, and each proton had been associated to the directly bound carbon through the HSQC spectrum, we could use the 2D HMBC NMR to merge all these moieties. Thus, cross-peaks of $\mathrm{H}-7$ with C-4, C-5, C-6 and C-9 confirmed the bibenzyl resorcinoid substructure, the network of cross-peaks of H-4 and H-6 allowed the carbon assignment of the tetrasubstituted phenyl ring and correlations of $\mathrm{H}_{2}-1$ ' with $\mathrm{C}-2, \mathrm{C}-3, \mathrm{C}-4$ located the prenyl unit at C-2, while the 2-methylbutanoyl group could be located at either phenolic hydroxyls due to the symmetry of the compound. The esterified phenolic carbon experienced the expected ${ }^{13} \mathrm{C}$ NMR upfield shift $(\delta \mathrm{C}: \mathrm{C}-1=155.8, \mathrm{C}-3=149.6)$. 
Compound $4\left(\mathrm{C}_{19} \mathrm{H}_{22} \mathrm{O}_{2}\right.$ by HR-ESIMS $)$ was found to be an analogue of $\mathbf{3 b}$ lacking the 2methylbutanoyl esterification and featuring cyclization of the prenyl unit to a chromane-type system. Accordingly, ${ }^{1} \mathrm{H}$ NMR resonances of the bibenzyl moiety of $\mathbf{4}$ were almost superimposable to parallel resonances of $\mathbf{3 b}$, while signals of the prenyl unit were replaced by two mutually coupled triplets $\left(\delta_{\mathrm{H}} 2.60\right.$ and 1.80$)$ and by a $6 \mathrm{H}$ singlet resonating at $\delta_{\mathrm{H}} 1.34$. Similarly to $3 \mathbf{b}$, the $2 \mathrm{D}$ HSQC spectrum associated the resonances of directly bound proton and carbon atoms, while the 2D HMBC showed key ${ }^{2,3} J_{\mathrm{C}, \mathrm{H}}$ cross-peaks. In particular, $\mathrm{H}_{2}-1$ ' correlated with C-1, C-2, C-3 and the oxygenated unprotonated $s p^{3}$ carbon $\mathrm{C}-3^{\prime}$, while $\mathrm{H}_{3}-4^{\prime} / \mathrm{H}_{3}-5^{\prime}$ exhibited cross-peaks with $\mathrm{C}-2^{\prime}$ and C3'. In agreement with the molecular formula and with the NMR resonance pattern of $\mathbf{4}$, an oxygen bridge between $\mathrm{C}-1$ and C-3' should complete the structure of this metabolite. Compound $\mathbf{4}$ is a new natural product, but it had been obtained semisynthetically by Asakawa et al. ${ }^{9}$ The (incomplete) spectral data reported are in agreement with ours.

Compound $5 \mathbf{a}\left(\mathrm{C}_{20} \mathrm{H}_{28} \mathrm{O}_{4}\right.$, negative ions HR-ESIMS) was characterized as a new phloroglucinol differing from $\mathbf{5 b}$ for the ketone-bearing side chain. In particular, signals of a geranyl moiety were easily recognizable in the ${ }^{1} \mathrm{H}$ NMR spectrum of $\mathbf{5 a}$, including two $s p^{2}$ methines $\left(\delta_{\mathrm{H}} 5.25\right.$ and 5.05), three allylic methylenes $\left(\delta_{\mathrm{H}} 3.38,2.10\right.$ and 2.08$)$ and three allylic methyl groups $\left(\delta_{\mathrm{H}} 1.80,1.67\right.$ and 1.59 , all bs). These signals were associated to those of corresponding carbons through the HSQC spectrum and then, via $\mathrm{HMBC}$, the prenyl unit could be attached at the $\mathrm{C}-2$ of a phloroglucinol moiety. In particular, cross-peaks of $\mathrm{H}_{2}-1$ ' with $\mathrm{C}-1, \mathrm{C}-2$ and $\mathrm{C}-3$ and of $\mathrm{H}-6$ with $\mathrm{C}-1, \mathrm{C}-2, \mathrm{C}-4$ and C-5 completely defined this portion of the molecule. The structure of compound $\mathbf{5 a}$ was completed by a linear $\mathrm{C}_{4}$ unit embedding a ketone carbonyl $\left(\delta_{\mathrm{C}} 205.9\right)$. Its attachment at C-4 was secured by HMBC cross-peaks of the deshielded $\mathrm{H}_{2}-8$ with the ketone C-7 and C-4.

The acids $\mathbf{3 c}$ and $\mathbf{3 d}$ were surprisingly stable under the conditions of decarboxylation of precannabinoids. ${ }^{7}$ Both compounds are acylated at the para-hydroxyl, and this structural feature might 
be responsible for their surprising thermal stability. Decarboxylation of $o$-hydroxybenzoic acids occurs via their non-aromatic carbonyl tautomer (Figure 1). A p-hydroxyl can stabilize by electron donation this tautomer, facilitating loss of carbon dioxide via the cyclic mechanism typical of $\beta$ ketoacids (Figure 1). Acylation of the $p$-hydroyl removes the mesomeric contribution to the stabilization of the carbonyl tautomer, providing a possible explaination for the increased thermal stability associated to this maneuver.

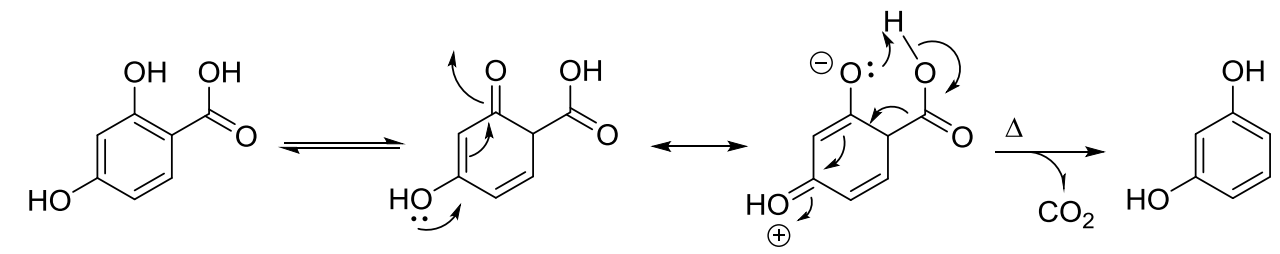

Figure 1. Mechanism of the thermal decarboxylation of 2,4-resorcinolcarboxylic acids.

The phenethyl analogue of CBG (Heli-CBG, 2a) and its lower prenylogues $\mathbf{3 a}, \mathbf{3 b}$ and $\mathbf{3 c}$ were assayed against a series of metabotropic $\left(\mathrm{CB}_{1}\right.$ and $\left.\mathrm{CB}_{2}\right)$ and ionotropic (thermo-TRPs) targets of phytocannabinoids, comparing their profile with the one of cannabigerol (1a, CBG). ${ }^{10,11} \mathrm{CBG}$ is a poor ligand of $\mathrm{CB}_{1}$ and $\mathrm{CB}_{2}$ (Table $1, \mathrm{Ki}=0.439 \pm 0.082 \mu \mathrm{M}$ and $0.337 \pm 0.034 \mu \mathrm{M}$, respectively $)^{10}$, and its phenethyl analogue $2 \mathbf{a}$ showed an even lower affinity $(\mathrm{Ki}=3.72 \pm 1.19 \mu \mathrm{M}$ and $0.828 \pm 0.094 \mu \mathrm{M}$, respectively). On the other hand, activity on thermo-TRPs was substantially retained (Table 1), and even increased in the case of antagonism to TRPM8 $(\mathrm{Ki}=1.38 \pm 0.12 \mu \mathrm{M}$ and $3.07 \pm 0.38 \mu \mathrm{M}$, respectively). TRPM8 is of considerable interest in cancer research, since hormone-dependent prostate and breast cancer cells over express this ion channel, ${ }^{12}$ and the biphenyl structural element of $\mathbf{2 a}$ could serve as a lead structure to develop compounds of therapeutic and/or diagnostic utility. ${ }^{12}$ Substantial retention of activity against TRPV2 and TRPV3 is also interesting, since these thermoTRPs are difficult to modulate with small molecules. Remarkably, the acylated lower prenylogue $\mathbf{3 b}$, a novel compound, was even more powerful than 
CBG and Heli-CBG on TRPV3, showing sub-micromolar affinity for this ion channel $\left(\mathrm{IC}_{50}=0.52\right.$ $\pm 0.07 \mu \mathrm{M}$ vs $1.72 \pm 0.06 \mu \mathrm{M}$ for Heli-CBG). Taken together, our bioactivity data suggest that the pentyl-to phenethyl structural modification is modestly detrimental for affinity with cannabinoid receptors. Conversely, activity is retained or even increased with thermo-TRPs, Remarkably, the acylated lower prenyl homologue $\mathbf{3 b}$ showed sub-micromolar affinity for TRPV3. Although activation of brain TRPV3 has been associated to anti-depressant and mood-relaxing activity, ${ }^{13,14}$ the low concentration of $\mathbf{3 b}$ in $H$. umbraculigerum and the lack of $\Delta^{9}$-THC or related alkyl-type cannabinoids in the sample we have investigated make unlikely that the inhalation of $H$. umbraculigerum vapors could induce narcotic effects.

Table 1. Comparative evaluation of CBG and Heli-CBG for the modulation of cannabinoid receptors and thermo-TRPs. All data are expressed in micromolar $(\mu \mathrm{M})$ concentrations.

\begin{tabular}{|c|c|c|}
\hline Biological end-point & $\begin{array}{l}\text { Cannabigerol } \\
(\mathrm{CBG}, \mathbf{1 a})\end{array}$ & $\begin{array}{r}\text { Helicannabigerol } \\
\text { (Heli-CBG, 2a) }\end{array}$ \\
\hline $\mathrm{CB}_{1}$ & $0.439 \pm 0082$ & $3.72 \pm 1.19$ \\
\hline $\mathrm{CB}_{2}$ & $0.337 \pm 0.034$ & $0.828 \pm 0.094$ \\
\hline $\begin{array}{l}\text { TRPV1 } \\
\left(\mathrm{I}_{\mathrm{C} 50} \text { capsaicin } 0.1 \mu \mathrm{M}\right)\end{array}$ & $4.12 \pm 0.23$ & $4.09 \pm 0.22$ \\
\hline $\begin{array}{l}\text { TRPV2 } \\
\left(\text { IC }_{50} \text { LPC } 3 \mu \mathrm{M}\right)\end{array}$ & $1.81 \pm 0.14$ & $6.29 \pm 0.22$ \\
\hline $\begin{array}{l}\text { TRPV3 } \\
\left(\mathrm{IC}_{50} \text { thymol } 100 \mu \mathrm{M}\right)\end{array}$ & $1.02 \pm 0.18$ & $1.72 \pm 0.06$ \\
\hline $\begin{array}{l}\text { TRPV4 } \\
\left(\mathrm{IC}_{50} 4 \alpha \mathrm{PDD} 1 \mu \mathrm{M}\right)\end{array}$ & $0.87 \pm 0.03$ & $2.91 \pm 0.18$ \\
\hline $\begin{array}{l}\text { TRPM8 } \\
\left(\mathrm{IC}_{50} \text { icilin } 0.25 \mu \mathrm{M}\right)\end{array}$ & $3.07 \pm 0.38$ & $1.38 \pm 0.12$ \\
\hline $\begin{array}{l}\text { TRPA1 } \\
\left(\text { IC }_{50} \text { AITC } 100 \mu \mathrm{M}\right)\end{array}$ & $1.17 \pm 0.08$ & $1.54 \pm 0.03$ \\
\hline
\end{tabular}




\section{Experimental Section}

\subsection{General Experimental Procedures}

Optical rotations $\left(\mathrm{CHCl}_{3}\right)$ were measured at $589 \mathrm{~nm}$ on a JASCO P2000 polarimeter and high performance liquid chromatography (HPLC) was performed on a Waters® apparatus equipped with a pump module 600 and a dual wavelength $(210,254 \mathrm{~nm})$ UV detector using Shimpack® Si 20*250 columns. ${ }^{1} \mathrm{H}(500 \mathrm{MHz})$ and ${ }^{13} \mathrm{C}(125 \mathrm{MHz})$ NMR spectra were measured on a Varian INOVA spectrometer. Chemical shifts were referenced to the residual solvent signal $\left(\mathrm{CDCl}_{3}: \delta_{\mathrm{H}}=7.26, \delta_{\mathrm{C}}=\right.$ 77.0). Homonuclear ${ }^{1} \mathrm{H}$ connectivities were determined by the COSY experiment. One-bond heteronuclear ${ }^{1} \mathrm{H}_{-}{ }^{13} \mathrm{C}$ connectivities were determined with the HSQC experiment. Two- and threebond ${ }^{1} \mathrm{H}-{ }^{13} \mathrm{C}$ connectivities were determined by gradient $2 \mathrm{D} \mathrm{HMBC}$ experiments optimized for a ${ }^{2,3} J=9 \mathrm{~Hz}$. Low- and high-resolution ESIMS were obtained on a LTQ OrbitrapXL (Thermo Scientific) mass spectrometer. Silica gels in different particle sizes used for open column chromatography. Compounds on the TLC (Silicagel $60 \mathrm{GF}_{254}$ precoated plates, Merck) were detected at 254 and $365 \mathrm{~nm}$, and by cerium sulfate molibdate as spraying reagent proceeded by heating. All reagents and solvents were purchased form Sigma-Aldrich, and the chromatographic stationary phases from Merck. Flash chromatography was carried out on Biotage SP-1 equipment, using Biotage Snap Ultra RP C-18, $12 \mathrm{~g}$ (particle size $25 \mu \mathrm{m}$ ). Acidified silica gel for GCC was prepared by treating silica gel with a water solution of $\mathrm{K}_{2} \mathrm{HPO}_{4}(4 \% \mathrm{w} / \mathrm{w}$ ratio), removal of water (rotavapor) and drying in oven at $150^{\circ}$ for $12 \mathrm{~h}$.

\subsection{Plant Material}

H. umbraculigerum was collected at the Walter Sisulu National Botanical Garden, Roodepoort, Johannesburg, South Africa. under permission of the South African Department of Environmental Affairs (permit BABS/000710N). A voucher specimen is stored in the HGWJ Schweickerdt 
Herbarium (PRU), University of Pretoria, South Africa. (Helichrysum umbraculigerum PRU 117100).

\subsection{Extraction and Isolation:}

The powdered plant material $(110 \mathrm{~g})$ was extracted with acetone at room temp. to afford $10.22 \mathrm{~g}$ of a dark brown extract $(9 \%)$, that was dissolved in the minimal amount of $\mathrm{MeOH}$ at $40{ }^{\circ} \mathrm{C}$, and then vacuum-filtered over a RP-18 silica gel $(30 \mathrm{~g})$ bed on a sintered glass $(9 \times 15 \mathrm{~cm})$. Elution with methanol (300 $\mathrm{mL})$ and evaporation afforded $5.1 \mathrm{~g}$ of a defatted greenish gum, that was fractionated by GCC on silica gel (250 g) using a petroleum ether/EtOAc gradient (from 7:3 to 3:7). The eluates $(20 \mathrm{~mL})$ were pooled according to their TLC profile in three main fractions. Fraction 1 (710 mg) was fractionated by GCC on acidified silica gel $(35 \mathrm{~g}, 5 \mathrm{~mL}$ volume fractions) with a petroleum ether/EtOAc gradient (from 8:2 to 6:4) to afford two subfractions (Ia and Ib, 173 and 117 mg, respectively). Subfraction Ia was purified flash chromatographer on a RP C-18 cartridge (12 g, $5 \mathrm{~mL}$ volume fractions) using a methanol/ $\mathrm{H}_{3} \mathrm{PO}_{4}(\mathrm{pH}=3)$ gradient, from 2:8 to 9:1) to afford 8 (65 $\mathrm{mg}$ ) as a white powder. A portion of subfraction $\mathrm{Ib}(57 \mathrm{mg})$ was purified by HPLC on silica gel (isocratic, $n$-hexane/EtOAc 6:4 as eluant) to give, in order of elution, 7a (3.2 mg, oil), $7 \mathbf{b}$ (3.4 mg, oil) and 6 (2.1 $\mathrm{mg}$, oil). The remaining portion $(65 \mathrm{mg})$ of fraction $\mathrm{Ib}$ was methylated with trimethylsilyldiazomethane $(2.0 \mathrm{M}$ in ethyl ether solution, $300 \mu \mathrm{L})$ in methanol $(2 \mathrm{~mL})$ to methylate fatty acids that interfered with the fractionation, and then purified by GCC on silica gel ( $4 \mathrm{~g}, 2 \mathrm{~mL}$ volume fractions, petroleum ether/EtOAc 8:2) to give a fraction that was further purified by HPLC HPLC on silica gel (isocratic, $n$-hexane/EtOAc 6:4 as eluant) affording $\mathbf{2 b}(0.8 \mathrm{mg}), \mathbf{5 b}(4.2 \mathrm{mg})$ and $\mathbf{5 a}(7.3 \mathrm{mg})$.

Fraction II and III (230 and $250 \mathrm{mg}$, respectively) contained a mixture of neutral and acidic cannabinoids, and were decarboxylated by heating at $120^{\circ} \mathrm{C}$ for $2.5 \mathrm{~h}$ and then purified by silica gel 
HPLC (isocratic, $n$-hexane/EtOAc 6:4) to afford, in order of elution, 2a (3.2 mg), 4 (3.7 mg), 3a (17.3 mg), and $\mathbf{3 b}$ (8.2 mg, oil) from fraction II, and 3d (30.2 mg), 3c (30.6 mg) from fraction III. 3.3.1 O-Methylbutyryl DeprenylHelycannabigenol (3b)

Colorless oil; $[\alpha]_{\mathrm{D}}-2.2\left(\mathrm{c} 0.02, \mathrm{CHCl}_{3}\right) ;{ }^{1} \mathrm{H} \mathrm{NMR}\left(\mathrm{CDCl}_{3}, 500 \mathrm{MHz}, J\right.$ in $\left.\mathrm{Hz}\right): \delta 7.35-7.15(5 \mathrm{H}$, overlapped, H-10 to H-14), 6.56 (1H, bs, H-6), 6.44 (1H, bs, H-4), 5.18 (1H, t, J=6.2, H-2'), 3.22 $\left(2 \mathrm{H}, \mathrm{d}, J=6.2, \mathrm{H}_{2}-1^{\prime}\right), 2.85-2.83\left(4 \mathrm{H}\right.$, overlapped, $\left.\mathrm{H}_{2}-7, \mathrm{H}_{2}-8\right), 2.63(1 \mathrm{H}$, hex, $J=7.2, \mathrm{H}-2 "), 1.85$ (1H, m, H-3"a), 1.79 (3H, s, H3-5'), 1.74 (3H, s, H $3^{-4}$ '), 1.61 (1H, m, H-3"b), 1.30 (3H, d, J = 7.2, $\left.\mathrm{H}_{3}-5^{\prime \prime}\right), 1.03$ (3H, t, $\left.J=7.2, \mathrm{H}_{3}-4 "\right) .{ }^{13} \mathrm{C} \mathrm{NMR}\left(\mathrm{CDCl}_{3}, 125 \mathrm{MHz}\right): \delta 175.7$ (s, C-1"), 155.8 (s, C-1), 149.6 (s, C-3), 142.0 (s, C-9), 141.9 (s, C-5), 135.6 (s, C-3'), 128.2 (d, C-11), 128.2 (d, C-13), 128.0 (C-14), 128.0 (d, C-10), 126.0 (d, C-12), 121.5 (d, C-2'), 117.4 (s, C-2), 114.7 (d, C-4), 113.9 (d, C6), 41.1 (d, C-2"), 37.8 (t, C-8), 37.7 (t, C-7), 26.2 (t, C-3"), 26.0 (q, C-4'), 23.6 (t, C-1'), 17.2 (q, C5'), 16.5 (q, C-5"), 11.1 (q, C-4"). HR-ESIMS found 389.2095; $\mathrm{C}_{24} \mathrm{H}_{30} \mathrm{NaO}_{3}$ requires 389.2093.

\subsubsection{Cyclodemethyldecarboxyamorfrutin $A(\mathbf{4})$}

Colorless amorphous solid; ${ }^{1} \mathrm{H}$ NMR $\left(\mathrm{CDCl}_{3}, 500 \mathrm{MHz}, J\right.$ in $\left.\mathrm{Hz}\right): \delta$ 7.30-7.15 (5H, overlapped, $\mathrm{H}-$ 10 to $\mathrm{H}-14), 6.31$ (1H, bs, H-6), $6.16(1 \mathrm{H}, \mathrm{bs}, \mathrm{H}-4), 2.85-2.82$ (4H, overlapped, $\left.\mathrm{H}_{2}-7, \mathrm{H}_{2}-8\right), 2.60$ $\left(2 \mathrm{H}, \mathrm{t}, J=6.2, \mathrm{H}_{2}-1^{\prime}\right), 1.80\left(2 \mathrm{H}, \mathrm{t}, J=6.2, \mathrm{H}_{2}-2^{\prime}\right), 1.34\left(6 \mathrm{H}, \mathrm{s}, \mathrm{H}_{3}-5{ }^{\prime}, \mathrm{H}_{3}-4^{\prime}\right) .{ }^{13} \mathrm{C} \mathrm{NMR}\left(\mathrm{CDCl}_{3}, 125\right.$ MHz): $\delta 156.8$ (s, C-3), 155.0 (s, C-1), 142.0 (s, C-9), 141.9 (s, C-5), 128.2 (d, C-11), 128.2 (d, C13), 128.0 (d, C-10), 128.0 (C-14) 126.0 (d, C-12), 110.0 (d, C-6), 107.5 (d, C-4), 107.0 (s, C-2), 74.8 (s, C-3'), 31.8 (t, C-2'), 37.8 (t, C-8), 37.7 (t, C-7), 25.6 (q, C-4'), 25.6 (q, C-5'), 16.2 (t, C-1'). HR-ESIMS found 305.1512; $\mathrm{C}_{19} \mathrm{H}_{22} \mathrm{NaO}_{2}$ requires 305.1517.

\section{3,3.3 Geranylphlorabutyrophenone (5a)}

Colorless amorphous solid; ${ }^{1} \mathrm{H} \mathrm{NMR}\left(\mathrm{CDCl}_{3}, 500 \mathrm{MHz}, J\right.$ in $\left.\mathrm{Hz}\right): \delta 5.84(1 \mathrm{H}, \mathrm{s}, \mathrm{H}-6), 5.25(1 \mathrm{H}, \mathrm{t}, J$ $\left.=6.2, \mathrm{H}-2^{\prime}\right), 5.05\left(1 \mathrm{H}, \mathrm{t}, J=6.2, \mathrm{H}^{-} 6^{\prime}\right), 3.38\left(2 \mathrm{H}, \mathrm{d}, J=6.2, \mathrm{H}_{2}-1^{\prime}\right), 3.02\left(2 \mathrm{H}, \mathrm{t}, J=6.8, \mathrm{H}_{2}-8\right), 2.10$ 
(2H, overlapped, $\left.\mathrm{H}_{2}-5^{\prime}\right), 2.08$ (2H, overlapped, $\left.\mathrm{H}_{2}-4^{\prime}\right), 1.80\left(3 \mathrm{H}, \mathrm{s}, \mathrm{H}_{3}-10^{\prime}\right), 1.71(2 \mathrm{H}$, hex, $J=6.8$, $\left.\mathrm{H}_{2}-9\right), 1.67\left(3 \mathrm{H}, \mathrm{s}, \mathrm{H}_{3}-8^{\prime}\right), 1.59\left(3 \mathrm{H}, \mathrm{s}, \mathrm{H}_{3}-9^{\prime}\right), 0.98\left(3 \mathrm{H}, \mathrm{t}, J=6.8, \mathrm{H}_{2}-10\right) .{ }^{13} \mathrm{C} \mathrm{NMR}\left(\mathrm{CDCl}_{3}, 125\right.$ MHz): $\delta 205.9$ (s, C-7), 163.6 (s, C-1), 161.6 (s, C-5), 160.5 (s, C-3), 140.0 (s, C-3'), 133.3 (s, C-7'), 123.8 (d, C-6'), 121.4 (d, C-2'), 105.5 (s, C-2), 104.0 (s, C-4), 97.2 (d, C-6), 46.6 (t, C-8), 39.6 (t, C4'), 25.4 (t, C-5'), 25.2 (q, C-8'), 20.9 (t, C-1'), 19.7 (t, C-9), 17.5 (q, C-9'), 15.3 (q, C-10'), 15.0 (q, C-10). HR-ESIMS found 305.1912; $\mathrm{C}_{20} \mathrm{H}_{27} \mathrm{O}_{4}$ requires 331.1909.

\subsection{Bioactivity assays}

\subsubsection{Cannabinoid $\left(\mathrm{CB}_{1}, \mathrm{CB}_{2}\right)$ receptor assays}

Membranes harvested from human recombinant $\mathrm{CB}_{1}(\mathrm{Bmax}=2.5 \mathrm{pmol} / \mathrm{mg}$ protein $)$ or $\mathrm{CB} 2(\mathrm{Bmax}=$ $4.7 \mathrm{pmol} / \mathrm{mg}$ protein) receptor transfected HEK-293 cells were incubated with the high affinity ligand $\left[{ }^{3} \mathrm{H}\right]-\mathrm{CP}-55,940\left(0.14 \mathrm{nM}, \mathrm{Kd}=0.18 \mathrm{nM}\right.$ or $0.084 \mathrm{nM}, \mathrm{Kd}=0.31 \mathrm{nM}$, respectively, for $\mathrm{CB}_{1}$ and $\mathrm{CB}_{2}$ ), and displaced with $10 \mu \mathrm{M}$ of the heterologous competitor for non specific binding WIN 55212-2 (Ki values $9.2 \mathrm{nM}$ and $2.1 \mathrm{nM}$, respectively, for the $\mathrm{CB}_{1}$ and $\mathrm{CB}_{2}$ ). All compounds were assayed according to the manufacturer's (Perkin Elmer, Milano, Italy) instructions. Increasing concentrations of compounds were incubated with $\left[{ }^{3} \mathrm{H}\right]-\mathrm{CP}-55,940$ for $90 \mathrm{~min}$ at $30{ }^{\circ} \mathrm{C}$ to generate displacement curves. $\mathrm{IC}_{50}$ values of the test compounds for the displacement of the bound radioligand were obtained by GraphPad $\operatorname{Prsim}^{\circledR}$ and used to calculate Ki values via the ChengPrusoff equation. Data represented as means \pm SEM of at least $n=3$ experiments.

\subsubsection{Thermo-TRPs (TRPV1, TRPV2, TRPV3, TRPV4, TRPM8, TRPA1) Receptor Assays}

HEK-293 cells stably over-expressing recombinant rat TRPA1, TRPM8, TRPV2-4, TRPM8 or human TRPV1 were selected by G-418 (Geneticin; $600 \mu \mathrm{g} \mathrm{ml}^{-1}$ ), grown on 100-mm diameter Petri dishes as monolayers in minimum essential medium supplemented with non-essential amino acids, $10 \%$ fetal bovine serum, and $2 \mathrm{mM}$ glutamine, and maintained under $5 \% \mathrm{CO}_{2}$ at $37{ }^{\circ} \mathrm{C}$. Stable expression of each channel was checked by quantitative real time-PCR. The effect of the substances 
on intracellular $\mathrm{Ca}^{2+}$ concentration $\left[\mathrm{Ca}^{2+}\right]_{i}$ was determined using Fluo-4, a selective intracellular fluorescent probe for $\mathrm{Ca}^{2+}$. Toward this aim, on the day of the experiment, cells overexpressing the TRP channels were loaded for $1 \mathrm{~h}$ in the dark at room temperature with the methyl ester Fluo4-AM (4 $\mu \mathrm{M}$ in dimethyl sulphoxide containing $0.02 \%$ Pluronic F-127, Invitrogen) in minimum essential medium without fetal bovine serum. After the loading, cells were washed twice in Tyrode's buffer (145 mM NaCl, $2.5 \mathrm{mM} \mathrm{KCl}, 1.5 \mathrm{mM} \mathrm{CaCl}, 1.2 \mathrm{mM} \mathrm{MgCl} 2,10 \mathrm{mM}$ D-glucose, and $10 \mathrm{mM}$ HEPES, pH 7.4), resuspended in Tyrode's buffer, and transferred (about 100000 cells) to the quartz cuvette of the spectrofluorimeter (Perkin-Elmer LS50B; PerkinElmer Life and Analytical Sciences, Waltham, MA) under continuous stirring. $\left[\mathrm{Ca}^{2+}\right]_{\mathrm{i}}$ was determined before and after the addition of various concentrations of test compounds by measuring cell fluorescence at $25{ }^{\circ} \mathrm{C}\left(\lambda_{\mathrm{EX}}=488 \mathrm{~nm}\right.$, $\lambda_{\mathrm{EM}}=516 \mathrm{~nm}$ ). Curve fitting (sigmoidal dose-response variable slope) and parameter estimation were performed with GraphPad Prism ${ }^{\circledR}$ (GraphPad Software Inc., San Diego, CA). Potency was expressed as the concentration of test substances exerting a half-maximal agonist effect (i.e., halfmaximal increases in $\left[\mathrm{Ca}^{2+}\right]_{\mathrm{i}}\left(\mathrm{EC}_{50}\right)$, calculated by using GraphPad ${ }^{\circledR}$. The efficacy of the agonists was first determined by normalizing their effect to the maximum $\mathrm{Ca}^{2+}$ influx effect on $\left[\mathrm{Ca}^{2+}\right]_{\mathrm{i}}$ observed with application of $4 \mu \mathrm{M}$ ionomycin (Sigma). The increases in fluorescence in wild-type HEK293 cells (i.e. not transfected with any construct) were used as baseline and subtracted from the values obtained from transfected cells. The effects of TRPA1 agonists are expressed as a percentage of the effect obtained with $100 \mu \mathrm{M}$ allyl isothiocyanate (AITC). In the case of TRPM8 the experiments were carried out at $22{ }^{\circ} \mathrm{C}$ with a Fluorescence Peltier System (PTP-1, PerkinElmer). Antagonist/desensitizing behaviour was evaluated against capsaicin $(0.1 \mu \mathrm{M})$ for TRPV1, icilin $(0.25 \mu \mathrm{M})$ for TRPM8; AITC $(100 \mu \mathrm{M})$ for TRPA1, lysophosphatidylcholine (LPC) $(3 \mu \mathrm{M})$

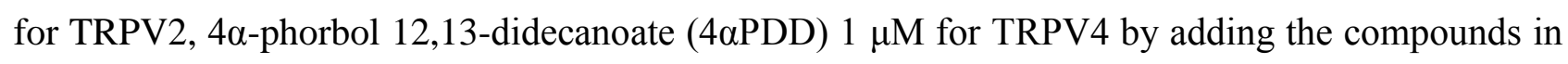
the quartz cuvette 5 min before stimulation of cells with agonists. In the case of TRPV3, rat TRPV3-expressing HEK-293 cells were first sensitized with the non-selective agonist 2- 
aminoethoxydiphenyl borate $(100 \mu \mathrm{M})$. Antagonist/desensitizing behavior was evaluated against thymol $(100 \mu \mathrm{M})$. Data are expressed as the concentration exerting a half-maximal inhibition of agonist $\left[\mathrm{Ca}^{2+}\right]_{\mathrm{i}}$ increasing effect $\left(\mathrm{IC}_{50}\right)$ which was calculated again using GraphPad Prism ${ }^{\circledR}$ software. The effect on $\left[\mathrm{Ca}^{2+}\right]_{\mathrm{i}}$ exerted by the agonist alone was taken as $100 \%$. All determinations were at least performed in triplicate. Statistical analysis of the data was performed by analysis of variance at each point using ANOVA followed by Bonferroni's test.

\section{Conclusions}

The use of Helichrysum species in ritual fumigations was already reported by Theophrastus in his Historia Plantarum, the oldest medicinal treatise of the Western civilization, ${ }^{15}$ and is also documented in the folk medicine of South Africa. ${ }^{16}$ Some Helichrysum species have also been used as marijuana substitutes ${ }^{17}$ but the identity of their mind-altering constituents is still elusive, and a confirmation of this activity in controlled studies is lacking. The sample of $H$. umbraculigerum we have investigated did not contain alkyl phytocannabinoids, but only phytocannabinoids of the aralkyl type, accompanied by their biogenetically related acylphloroglucinoids. Nevertheless, given the high variability of the secondary metabolism of plants from the Helichrysum species, we cannot rule out that the profligacy of these plants to couple the polyketide and the isoprenoid pathways could result in the production of narcotic phytocannabinoids, and/or, of powerful lingands of TRPV3.

\section{Conflict of interest}

The authors declare no conflict of interest.

\section{Acknowledgements}

This research did not receive any specific grant from funding agencies in the public, commercial, or non-for-profit sectors. We are grateful to Mrs. Kirsty S Botha for the picture of Helichrysum umbraculigerum. 


\section{References}

[1] L. O. Hanuš, S. M. Meyer, E. Muñoz, O. Taglialatela-Scafati, G. Appendino, Phytocannabinoids: a unified critical inventory. Nat. Prod. Rep. 33 (2016) 1357-1392. |

[2] C. del Río, C. Navarrete, J. A. Collado, M. L. Bellido, M. M. Gómez-Cañas, R. Pazos, J. J. FernándezRuiz, F. Pollastro, G. Appendino, M. A. Calzado, I. Cantarero, E. Muñoz, The cannabinoid quinol VCE004.8 alleviates bleomycin-inducedscleroderma and exerts potent antifibrotic effects through peroxisome proliferator-activated receptor- $\gamma$ and CB2 pathways. SciRep 6 (2016) 21703.

[3] L. Fuhr, M. Rousseau, A. Plauth, F. C. Schroeder, S. Sauer, Amorfrutins are natural PPAR $\gamma$ agonists with potent antiinflammatory properties. J. Nat. Prod. 78 (2015) 1160-1164.

[4] F. Bohlmann, E. Hoffmann, Cannabigerol-ähnliche Verbindungen aus Helichrysum umbraculigerum. Phytochemistry 18 (1979) 1371-1374.

[5] T. Long, M. Wagner, D. Demske, C. Leipe, P. E. Tarasov, Cannabis in Eurasia: origin of human use and Bronze Age continental connections. Veget. Hist. Archaeobot. 26 (2017), 245-258.

[6] https://www.shamansgarden.com/p-93-imphepho-helichrysum-odoratissimum.aspx (accessed on August 4, 2017).

[7] O. Taglialatela-Scafati, A. Pagani, F. Scala, L. De Petrocellis, V. Di Marzo, G. Grassi, G. Appendino, Cannabimovone, a cannabinoid with a rearranged terpenoid skeleton from hemp. Eur. J. Org. Chem. (2010), 2067-2072.

[8] J. Jakupovic, C. Zdero, M. Grenz, F. Tsichritzis, L. Lehmann, S.M. Hashemi-Nejad, F. Bohlmann, Twenty-one acylphloroglucinol derivatives and further constituents from south african Helichrysum species. Phytochemistry 1989 (28), 1119-1131.

[9] Y. Asakawa, K. Kondo, M. Tori, T. Hashimoto, S. Ogawa, Prenyl bibenzyls from the liverwort Radula kojana. Phytochemistry 30 (1991) 219-234.

[10]F. Pollastro, O. Taglialatela-Scafati, M. Allarà, E. Muñoz, V. Di Marzo, L. De Petrocellis, G. Appendino, Bioactive prenylogous cannabinoid from fiber hemp (Cannabis sativa). J. Nat. Prod. 74 (2011) 2019-2122. 
[11]L. De Petrocellis, V. Vellani, A. Schiano-Moriello, P. Marini, P. C. Magherini, P. Orlando, V. Di Marzo, Plant-derived cannabinoids modulate the activity of transient receptor potential channels of ankyrin type1 and melastatin type-8. J. Pharmacol. Exp. Ther. 325 (2008) 1007-1015.

[12] M. J. Pérez de Vega, I. Gómez-Monterrey, A. Ferrer-Montiel, R. González-Muñiz, Transient Receptor Potential Melastatin 8 Channel (TRPM8) modulation: Cool entryway for treating pain and cancer. J. Med. Chem. 59 (2016) 10006-10029.

[13] A. Moussaieff, N. Rimmerman, T. Bregman, A. Straiker, C. C. Felder, S. Shoham, Y. Kashman, S. M. Huang, H. Lee, E. Shohami, K. Mackie, M. J. Caterina, J. M. Walker, E. Fride, R. Mechoulam, Incensole acetate, an incense component, elicits psychoactivity by activating TRPV3 channels in the brain. FASEB J. (2008) 3024-3034.

[14]F. Pollastro, S. Golin, G. Chianese, M. Y. Putra, A. Schiano Moriello, L. De Petrocellis, V. García, E. Munoz, O. Taglialatela-Scafati, G. Appendino, Neuroactive and anti-inflammatory frankincense cembranes: A structure-sctivity study. J. Nat. Prod. 79 (2016) 1762-1768.

[15] For a commented edition of Theophrastus's Historia plantarum, see: S. Amigues, Théophraste, Recherches sur les plantes, À l'origine de la botanique. Paris, Belin, 2010.

[16] P. A. G. M. de Smet. Considerations in the multidisciplinary approach to the study of ritual hallucinogenic plants. In Ethnobotany: Evolution of a discipline (R. Evans Schultes and S. von Reis Ed.) (1995), Discorides Press, Portland, Ore., pp. 369-383

[17] C. Ratsch. The Encyclopedia of psychoactive plants. (1998), Park Street Press, Rochester, Verm., p. 141. 